\title{
Medical Expenses of North Korean Defectors with Post-Traumatic Stress Disorder
}

\author{
Jin-Won Noh ${ }^{1,2}$, Yejin Lee ${ }^{1}$, Hyunchun Park ${ }^{3}$, and So Hee Lee ${ }^{4 凶}$ \\ ${ }^{1}$ Department of Healthcare Management, Eulji University, Seongnam, Republic of Korea \\ ${ }^{2}$ Global Health Unit, Department of Health Sciences, University Medical Centre Groningen, University of Groningen, Groningen, Netherland \\ ${ }^{3}$ Gyeonggi Public Health Policy Institute, Seongnam, Republic of Korea \\ ${ }^{4}$ Department of Psychiatry, National Medical Center, Seoul, Republic of Korea
}

Objective The purpose of this study was to establish the prevalence of PTSD among North Korean defectors who visited the National Medical Center, Seoul, South Korea over a period of approximately 10 years by examining their medical records and to examine differences in the medical service usage patterns of patients with and without PTSD.

Methods Data from North Korean defectors who used outpatient services at the National Medical Center during a period of 10 years and 3 months (January 12006 to February 28, 2016) were analyzed. The general characteristics of the defectors were analyzed by frequency analyses, and descriptive statistics were generated. Additionally, independent t-tests and chi square analyses were performed to examine differences between PTSD patients and those without PTSD. Linear regression analysis was performed to examine factors affecting the mental health of North Korean defectors suffering from PTSD.

Results This study assessed the correlations between PTSD, the average number of outpatient visits, and the total revenue. The regression analysis showed a relationship between PTSD and the average number of outpatient visits. There was also a correlation between PTSD and total revenue. The average number of outpatient visits was 41.8 for PTSD patients, whereas it was 33.2 for those without PTSD. The total revenue visit was 953.6 USD for PTSD sufferers and 231.1 USD for those without PTSD.

Conclusion This study found that the majority of North Korean defectors visit psychiatry departments, and that PTSD patients use outpatient services more frequently and have higher total revenue than those without PTSD. Additionally, patients with PTSD used a greater variety of medical services. Considering the high medical care expenses of North Korean defectors residing in South Korea, future investigations should examine the medical service usage patterns of such patients, especially those diagnosed with PTSD, in greater detail.

Psychiatry Investig 2019;16(2):154-158

Key Words Post-traumatic stress disorder, North Korean defectors, Medical expenses.

\section{INTRODUCTION}

The number of North Korean defectors settling in South Korea has grown rapidly since the mid-1990s, when North Korea's food shortage problem worsened significantly. The cumulative number of North Korean defectors who had entered South Korea was approximately 1,000 in 2002, and it exceeded 10,000 by February 2007; by March 2016, the num-

Received: April 6, 2018 Revised: October 21, 2018

Accepted: December 12, 2018

$\triangle$ Correspondence: So Hee Lee, $\mathrm{MD}, \mathrm{PhD}$

Department of Psychiatry, National Medical Center, 245 Eulji-ro, Jung-gu, Seoul 04564, Republic of Korea

Tel: +82-2-2260-7311, Fax: +82-2-2268-5028, E-mail: psyhee@hanmail.net

(c) This is an Open Access article distributed under the terms of the Creative Commons Attribution Non-Commercial License (https://creativecommons.org/licenses/bync/4.0) which permits unrestricted non-commercial use, distribution, and reproduction in any medium, provided the original work is properly cited. ber had grown to $29,137 .{ }^{1}$ As the number of North Korean defectors settling in South Korea continues to increase, there is heightened interest in their ability to adapt to South Korean society. ${ }^{2}$

The South Korean government has implemented a variety of supportive policies, such as the Act for the Protection and Settlement Support of North Korean Defectors (enacted on April 14, 1997), to ensure that North Korean defectors living in South Korea can be self-reliant and self-sufficient. In 2012, the South Korean government expanded its resettlement facilities for North Korean defectors (named 'The 2nd Hana Won'), strengthened its special education programs for female defectors, and increased efforts to support the psychological stability and health of North Korean refugees. Additionally, the Ministry of Labor, in collaboration with private businesses and companies, launched the 'Job Creation Project 
for North Korean Defectors' program to address the employment problems that defectors cite as their greatest challenge. In September 27, 2010, the Act for the Protection and Settlement Support of North Korean Defectors was revised to encompass the Foundation for Supporting North Korean Defectors and the North Korean defector preparatory school scheme and to provide greater support for securing employment. ${ }^{1}$

Despite these continuing efforts at the national level, North Korean defectors, particularly the absolute poor, continue to struggle with social adjustment and mental illnesses. The mental illnesses in this population are primarily associated with the actual process of defection and the period of residence in a third country. In the mid-1990s, when there were still relatively few defectors, China accepted some refugees in response to the food shortages in North Korea. However, as the number of North Korean defectors grew over a prolonged period, China altered its position and began to repatriate the defectors. ${ }^{3,4}$ This forced repatriation made settling in China an uncomfortable process, rendering North Korean defectors psychologically vulnerable due to the threat to their basic rights.

The psychological effects of the persistent and complex traumatic experiences of North Korean defectors account for $29.5 \%$ of all post-traumatic stress disorder (PTSD) cases in this population. ${ }^{5}$ PTSD is a chronically relapsing condition characterized by the avoidance of places and behaviors related to the trauma and by symptoms (e.g., hyperactivity) that can manifest after stressful events (e.g., car accidents, wars, natural disasters, and rape) involving serious physical injury. The vivid traumatic experiences that characterize defection from North Korea, such as human rights abuses, family breakups, beatings, violence, imprisonment, and starvation, represent the main causes of PTSD. ${ }^{6}$

Among the various stressors experienced by North Korean defectors, the fear of trafficking is the most frequently cited (by $83.4 \%$ of defectors). ${ }^{7}$ In total, $56 \%$ of North Korean defectors residing in China and 9.2\% under the care of Chinese protection agencies reported suffering from PTSD. ${ }^{8,9}$ Based on consultations with 133 defectors residing in South Korea, Doctors Without Borders reported that $18.2 \%$ of North Korean refugees experienced difficulties due to PTSD. ${ }^{8-11}$ In general, the psychological impact of defection increases an individual's vulnerability to future stressors, thereby constituting a sustained and persistent effect. ${ }^{10,12}$

In many cases, PTSD causes somatic symptoms that result in both physical and mental illnesses. A survey conducted using the Patient Health Questionnaire-15 (PHQ-15) to measure somatization among North Korean defectors showed that this population tended to experience more somatic symptoms than the general South Korean population. ${ }^{13}$ Physical ill- nesses increase medical service use, which, in turn, increases total medical costs. The presence of PTSD among North Korean defectors increases care-related expenditures at both the societal and the individual levels. Thus, the effects of PTSD go beyond the suffering of those who actually have this condition and should be managed in a wider socio-economic context.

The purpose of this study was to investigate the rate of PTSD among North Korean defectors by examining the medical records of refugees who visited the National Medical Center, Seoul, Korea over a period of approximately 10 years and to examine patterns of medical service use according to the presence of PTSD. This study also aimed to contribute to the development of a systematic mental health care system designed specifically for North Korean defectors and to clarify the current mental health status of this group in preparation for any future unification of Korea.

\section{METHODS}

\section{Subjects and data}

Since 2006, the National Medical Center has treated approximately 4,000 North Korean defectors. Missing or duplicated electronic medical record (EMR) data are corrected and re-extracted, and included the records that are not supported by Public Health Services. Gaps in medical records are addressed by searching for missing codes and information within the EMRs. Data that have been subject to doubleentry are resolved, and data extracted from medical records are compared with those held by the Public Health Service. Medical records and Public Health data are re-extracted until they show sufficient similarity, and used the matching information to backtrack and compile missing data of order communication system (OCS).

The EMR data analyzed in this study were obtained from North Korean defectors using the outpatient services at the National Medical Center over a period of 10 years and 3 months. The study was carried out after approval was granted by our Institutional Review Board (approval number: H-1712-085001).

\section{Variables and measurements}

Regarding the general characteristics of the study subjects, age was recorded as the western age, and gender was coded as either male or female. All patients visiting the National Medical Center received medical care, health insurance, and general treatment (none of insurance), but we analyzed the data from only those who were treated at the Psychiatry Department.

Average number of visits was defined as the sum of outpatient visits numbers in the psychiatry department. Average 
revenue per visit was defined as the average revenue of each visit in psychiatry department. The total revenue was estimated as the sum of revenues, earned by the National Medical Center, such as the benefit income, non-reimbursed revenue, selected treatment income, and the copayment for each outpatient visit. PTSD group was defined as having diagnosed in clinical route (ICD-10: F43.1) and having experienced in treatment at least once by medical record.

\section{Statistical analysis}

The general characteristics of the North Korean defectors treated at the National Medical Center were analyzed by frequency analysis; descriptive statistics were also generated. Independent t-tests and chi-square analyses were performed to examine differences between the PTSD and non-PTSD groups. Linear regression analysis was performed to identify the factors that had the strongest effect on the mental health of the North Korean defectors with PTSD. Stata software (ver. 13.1; Stata Corp., College Station, TX, USA) was used to analyze the data, and $\mathrm{p}<0.05$ was taken to indicate statistical significance (two-tailed).

\section{RESULTS}

The average age of the North Korean defectors was 38.8 years; $23.8 \%$ were male, and $76.2 \%$ were female. The large majority of defectors $(98.4 \%)$ were medical benefits recipients, and $15.5 \%$ of this group used neuropsychiatry treatment. The average number of visits was 14.7 , and the average revenue per visit was 48.2 USD.

Among those defectors who visited the Psychiatry Department, $83.7 \%$ were female and $96.8 \%$ received medical benefits. The average number of visits was 37.1 , and the aver- age revenue per visit for psychiatry was 39.3 USD (Table 1).

The average number of visits was 41.8 among PTSD patients, and it was 33.2 among patients without PTSD. The revenue was 953.6 USD among PTSD sufferers, and it was 231.1 USD among those without PTSD (Table 2).

Data on the average number of visits by North Korean defectors and the total revenue of all National Medical Center departments were evaluated according to PTSD status.

Table 1. General characteristics of North Korean defectors

\begin{tabular}{|c|c|c|}
\hline & Total $(3,974)$ & $\begin{array}{c}\text { Visited the } \\
\text { psychiatry } \\
\text { department (602) }\end{array}$ \\
\hline & $\overline{\mathrm{N}(\%), \mathrm{M} \pm \mathrm{SD}}$ & $\mathrm{N}(\%), \mathrm{M} \pm \mathrm{SD}$ \\
\hline Age & $38.8 \pm 15.7$ & $44.2 \pm 13.3$ \\
\hline \multicolumn{3}{|l|}{ Sex } \\
\hline Male & $947(23.8)$ & $98(16.2)$ \\
\hline Female & $3,027(76.2)$ & $504(83.7)$ \\
\hline \multicolumn{3}{|l|}{ Insurance } \\
\hline Medical care & 3,911 (98.4) & $583(96.8)$ \\
\hline Health insurance & $38(1.0)$ & $19(3.2)$ \\
\hline None (general treatment) & $25(0.6)$ & \\
\hline \multicolumn{3}{|l|}{ Neuropsychiatry treatment } \\
\hline Yes & $602(15.5)$ & \\
\hline No & $3,372(84.5)$ & \\
\hline Average number of visits & $14.7 \pm 26.8$ & $37.1 \pm 46.3$ \\
\hline $\begin{array}{l}\text { Average revenue per visit for } \\
\text { psychiatry (USD) }\end{array}$ & $48.2 \pm 63.4$ & $39.3 \pm 27.2$ \\
\hline Average revenue (USD) & & $51.4 \pm 95.3$ \\
\hline $\begin{array}{l}\text { Average number of visits in } \\
\text { psychiatry }\end{array}$ & & $9.9 \pm 16.5$ \\
\hline
\end{tabular}

SD: standard deviation

Table 2. Comparison of general characteristics according to PTSD status

\begin{tabular}{|c|c|c|c|c|}
\hline & No PTSD (330) & PTSD (272) & t & $\mathrm{n}$ \\
\hline & $\mathrm{N}(\%), \mathrm{M} \pm \mathrm{SD}$ & $\mathrm{N}(\%), \mathrm{M} \pm \mathrm{SD}$ & l & $\mathrm{p}$ \\
\hline$\overline{\text { Age }}$ & $42.4 \pm 14.0$ & $46.3 \pm 12.1$ & -3.63 & $<0.01$ \\
\hline Sex & & & -1.84 & 0.07 \\
\hline Male & $62(18.8)$ & $36(13.2)$ & & \\
\hline Female & $268(81.2)$ & $236(86.8)$ & & \\
\hline Insurance type & & & -0.19 & 0.85 \\
\hline Medical care & $320(97.0)$ & $263(96.7)$ & & \\
\hline Health insurance & $10(3.0)$ & $9(3.3)$ & & \\
\hline Average number of visits & $33.2 \pm 43.2$ & $41.8 \pm 49.5$ & -2.27 & 0.02 \\
\hline Average number of visits in psychiatry & $9.2 \pm 13.5$ & $10.6 \pm 19.4$ & -1.05 & 0.29 \\
\hline Total revenue (USD) & $231.1 \pm 476.0$ & $953.6 \pm 1,310.4$ & -9.30 & $<0.01$ \\
\hline Total revenue for psychiatry (USD) & $538.4 \pm 923.8$ & $580.5 \pm 1,114.6$ & -0.51 & 0.61 \\
\hline
\end{tabular}

PTSD: Post-Traumatic Stress Disorder, M: mean, SD: standard deviation 
Regression analysis showed a correlation between the presence of PTSD and the average number of outpatient visits and between the presence of PTSD and the total revenue of all National Medical Center departments (Table 3).

\section{DISCUSSION}

The purpose of this study was to use EMR data to investigate the prevalence of PTSD among North Korean defectors who visited the National Medical Center over a period of approximately 10 years and to examine the different patterns of medical service usage according to the presence of PTSD.

Among refugees who visited the Psychiatry Department, those with a primary diagnosis of PTSD used psychiatric services more frequently than those without PTSD. In particular, the total revenue of patients with PTSD was almost three times higher than of those without PTSD, and the total revenue of the Psychiatry Department was also higher of patients with PTSD than of those without PTSD. Previous studies have demonstrated increased rates of medical service usage among patients with a diagnosis of PTSD. ${ }^{14}$

The high rate of medical service usage among North Korean defectors diagnosed with PTSD is due to the presence of somatic symptoms that result in both physical and mental illnesses. PTSD is associated with increased psychiatric morbidity, medical utilization and costs. ${ }^{15-17}$ Mental illnesses, including PTSD, can increase vulnerability to physical ailments. A cross-sectional study investigating severely traumatized defectors and asylum seekers residing in Switzerland found that severity of PTSD symptoms was significantly associated with

Table 3. Average number of visits by North Korean defectors and total revenue of all National Medical Center departments by PTSD status

\begin{tabular}{lccccc}
\hline & \multicolumn{2}{c}{$\begin{array}{c}\text { Average number } \\
\text { of visits }\end{array}$} & & \multicolumn{2}{c}{ Total revenue } \\
\cline { 2 - 3 } \cline { 5 - 6 } \cline { 5 - 6 } $\begin{array}{l}\text { Age } \\
\text { Sex }\end{array}$ & 0.05 & 0.26 & & 0.04 & 0.25 \\
$\quad$ Male & & & & & \\
$\quad$ Female & ref & & & \\
Insurance type & -0.03 & 0.50 & & 0.06 & 0.15 \\
$\quad$ Medical care & & & & & \\
$\quad$ Health insurance & 0.00 & 1.00 & & -0.02 & 0.61 \\
PTSD diagnosis & & & & & \\
$\quad$ No & ref & & & & \\
$\quad$ Yes & 0.09 & 0.03 & & 0.34 & $<0.01$ \\
Average number of visits & & & & 0.08 & 0.03 \\
\hline
\end{tabular}

PTSD: Post-Traumatic Stress Disorder somatization and explosive anger. ${ }^{18}$ Another cross-sectional study of defectors residing in Norway who were in outpatient psychiatric treatment and who had experienced traumatic events found that chronic clinically significant pain was present in $66 \%$ of all the patients and in $88 \%$ of those with a current PTSD diagnosis. The most common locations of chronic pain were the head (80\%), chest (74\%), arms/legs (66\%), and back (62\%), and females had significantly more chronic pain sites than men. Comorbid PTSD and chronic pain was seen in $57 \%$ of the outpatients. ${ }^{19}$ Other studies have shown that PTSD sufferers tend to be more likely to report nonspecific somatic complaints than those without PTSD, ${ }^{20-22}$ even when there are no differences in the physical and laboratory test results of the two groups. ${ }^{23,24}$

High rates of physical illness lead to increased medical service use, which, in turn, is directly linked to higher medical costs. Therefore, the presence of PTSD increases the likelihood of medical service usage. PTSD can no longer be considered a burden only to individuals; it also represents a socioeconomic problem at the societal level. According to the North Korean Defectors Survey, 38.3\% of North Korean refugees expressed a desire for medical support; this constituted their second-highest priority, after only economic support. ${ }^{25}$ In this study, only $15.5 \%$ of North Korean defectors visited the Psychiatry Department, but $45.2 \%$ of those had a diagnosis of PTSD. In several studies, the prevalence of PTSD among North Korean refugees in the community was about $0 \%{ }^{5,7,26}$ The PTSD rate among the defectors in this study may have been higher because they were psychiatry outpatients. Considering the relatively high PTSD prevalence of North Korean Defectors in South Korea (1.5\%), a health care plan targeting this population is required. ${ }^{27}$

Because the majority of North Korean defectors are diagnosed with PTSD due to serious trauma experienced during their escape, approaches to managing the mental health of this group that focus on PTSD should be a top priority. In policy terms, we believe that well-defined and precisely targeted researches and strategies are required to determine the mental health status of North Korean defectors, especially those with a diagnosis of PTSD, and to reduce the cost of their medical care. Ultimately, the social 'safety net' must be widened to improve the short-term mental health of North Korean defectors as well to reduce their long-term medical costs.

This study had several limitations. First, the study population was not representative of all North Korean defectors, as it relied only on the medical records of defectors who visited the National Medical Center. However, it is representative of those who visited the medical institution that treated the most North Korean defectors in South Korea and that established a specialized refugee treatment center. Second, the re- 
liability of medical records or diagnosis could be biased in this population because this is a retrospective study using medical record. Third, this study did not consider certain factors associated with PTSD and other mental health conditions due to a lack of available data. However, socioeconomic factors, such as income and educational level, have been associated with PTSD and medical service use rates. ${ }^{2,28}$ Fourth, this study did not measure the severity of PTSD, which may have varied significantly among patients. Fifth, North Korean defectors who did not visit the National Medical Center were not evaluated. North Koran defectors who do not visit a hospital but nevertheless suffer from severe PTSD may differ from those who do present at medical facilities.

Despite its limitations, this study closely examined the relationship between PTSD status (present or absent) and the rate of medical service usage by reference to the EMRs of North Korean defectors who visited the National Medical Center. The majority of the defectors visited the Psychiatry Department, and those with a diagnosis of PTSD had a higher average number of outpatient visits and higher total revenue. Additionally, such patients used a greater number of medical services. Additionally, when South Korea and North Korea are unified in the future, medical usage and expenses are expected to increase exponentially. Therefore, it is necessary to estimate the cost of medical treatment considering North Korean defectors' medical usage. This study implies that North Korean defectors with PTSD diagnose have higher medical expenditure than those who were not diagnosed. Considering the high medical expenses of North Korean defectors residing in South Korea, further investigations should examine differences in medical service use patterns according to PTSD status.

\section{Acknowledgments}

This study was supported by a grant from the Korean Mental Health Technology R\&D Project, Ministry of Health \& Welfare, Republic of Korea (HM15C1054).

\section{REFERENCES}

1. Ministry of Unification. Settlement Support for North Korean Defectors. 2018. Available at: http://www.unikorea.go.kr/content.do? $\mathrm{cmsid}=$ 1440. Accessed 1 January, 2018.

2. Han NY, Lee SH, Yoo SY, Kim SJ, Jun JY, Won SD, et al. Predictors of PTSD among North Korean defectors visited psychiatric department of North Korean defectors treatment center. J Korean Neuropsychiatr Assoc 2015;54.1;105-111.

3. Kang CY. The stress coping style of the female North Korean refugees in China. Korean J Woman Psychol 2005;10;61-80.

4. Yoon YS. Actual Situation of Overseas North Korean Defectors. London: The 8th Academy for North Korean Human Rights \& Refugees; 2004.

5. Hong CH, Yoo JJ, Cho YA, Eom J, Ku H, Seo SW, et al. A 3-year follow-up study of posttraumatic stress disorder among North Korean defectors. J Korean Neuropsychiatr Assoc 2006;45.1;49-56.
6. American Psychiatric Association. Diagnostic and Statistical Manual of Mental Disorders-IV-TR. Washington, DC: American Psychiatric Association; 2000.

7. Kang SR. Development of Trauma Scale for North Korean Refugee. Seoul: Department of Psychology, the Graduate School Yonsei University; 2001.

8. Lee, Y, Lee MK, Chun KH, Lee KY, Yoon JS. Trauma experience of North Korean refugees in China. Am J Prev Med 2001;20.3;225-229.

9. Yu SE, Jeon WT. Mental health of North Korean refugees in protective facilities in China. Psychiatry Investig 2008;5:70-77.

10. Medicines Sans Frontiers. Psychological Support for North Koreans defectors in South Korea. Geneva: 2005 Annual Report; 2006.

11. Cho Y, Kim Y, You S. Predictors of Mental Health among North Korean defectors residing in South Korea over 7 years. Korean J Counsel Psychother 2009;21.1;329-348.

12. Kim HK. The Psychological Impact and Recovery Experience of North Korean Defectors. Seoul: KSI; 2009.

13. Lee SH, Kim SJ, Shin MN, Jeon HY. Development Guideline for Improving Recognition of North Korean Defectors. Seoul: National Medical Center; 2013.

14. Campbell DG, Felker BL, Liu CF, Yano EM, Kirchner JE, Chan D, et al. Prevalence of depression-PTSD comorbidity: implications for clinical practice guidelines and primary care-based interventions. J Gen Intern Med 2007:22;711-718.

15. Solomon SD, Davidson JR. Trauma: prevalence, impairment, service use, and cost. J Clin Psychiatry 1997;58(Suppl 9):5-11.

16. Holman EA, Silver RC, Waitzkin H. Traumatic life events in primary care patients: A study in an ethnically diverse sample. Arch Fam Med 2000;9:802-810.

17. Ouimette P, Cronkite R, Henson BR, Prins A, Gima K, Moos RH. Posttraumatic stress disorder and health status among female and male medical patients. J Trauma Stress 2004;17;1-9.

18. Spiller TR, Schick M, Schnyder U, Bryant RA, Nickerson A, Morina N. Somatisation and anger are associated with symptom severity of posttraumatic stress disorder in severely traumatised refugees and asylum seekers. Swiss Med Wkly 2016;146;w14311.

19. Teodorescu DS, Heir T, Siqveland J, Hauff E, Wentzel-Larsen T, Lien L. Chronic pain in multi-traumatized outpatients with a refugee background resettled in Norway: a cross-sectional study. BMC Psychol 2015:3;7.

20. McFarlane AC, Atchison M, Rafalowicz E, Papay P. Physical symptoms in post-traumatic stress disorder. J Psychosom Res1994;38;715-726.

21. Baker DG, Mendenhall CL, Simbartl LA, Magan LK, Steinberg JL. Relationship between posttraumatic stress disorder and self-reported physical symptoms in Persian Gulf War veterans. Arch Intern Med 1997; 157:2076-2078.

22. Schnurr PP, Jankowski MK. Physical health and post-traumatic stress disorder: review and synthesis. Semin Clin Neuropsychiatry 1999;4:295304.

23. Shalev A, Bleich A, Ursano RJ. Posttraumatic stress disorder: somatic comorbidity and effort tolerance. Psychosomatics 1990;31:197-203.

24. Litz BT, Keane TM, Fisher L, Marx B, Monaco V. Physical health complaints in combat-related post-traumatic stress disorder: a preliminary report. J Trauma Stress 1992;5:131-141.

25. Korea Hana Foundation. Seoul: 2016 North Korean Defectors Settlement; 2017.

26. Park SJ, Kim NH, Jeong HY, Lee S. Comorbidity of posttraumatic stress disorder and its effect on treatment outcomes in patients with schizophrenia: one-year prospective follow-up study. Korean J Biol Psychiatry 2009:16;256-265.

27. Ministry of Health and Welfare. Sejong: The Survey of Mental Disorders in Korea; 2016.

28. Kim YH, Jeon WT, Cho YA. A study on the prevalence and the influencing factors of the mental health problems among recent migrant North Koreans: a focus on 2007 entrants. Unific Policy Stud 2010;19:141-174. 